\title{
Foreword
}

\section{The 5th International Conference on Biomedical Engineering and Biotechnology}

\author{
Edward J. Ciaccio ${ }^{\mathrm{a}, *}$ and Feng Liu ${ }^{\mathrm{b}}$ \\ ${ }^{a}$ Department of Medicine, Columbia University, New York, NY, USA \\ ${ }^{\mathrm{b}}$ International School of Software, Wuhan University, Wuhan, China
}

The 5th International Conference on Biomedical Engineering and Biotechnology (ICBEB 2016) was held from August 1st-4th, 2016 in Hangzhou, China. The event brought together hundreds of leading scientists and engineers from academia, industry, and government agencies, to present and discuss the latest technological innovations in the field. These included topics of bioengineering, biomaterials, biomedical imaging, and biomechanical engineering, as well as more clinically-related disciplines.

The iCBEB meeting is a yearly event, and is becoming a leading mode for international cooperation and collaboration in biotechnology. More than 1,000 papers are sent to the iCBEB each year for presentation in oral or written form. Of, these, approximately 200 are selected for actual conference presentation by the reviewers and the Committee. The language of the conference, for both abstracts and oral and written presentation, is English. Groups from all over the world, including many throughout Asia, Europe, and the Americas, submit their work for presentation.

In this focus, we are delighted to present the 49 papers which were selected by peer review as the top presentations of the meeting. The papers were first presented in oral or written form at iCBEB 2016 by the authors. Those authors with outstanding work were notified that their papers were candidates to publish in journal form, and were asked to revise and expand their work for that format. The manuscripts were screened and reviewed. Manuscripts with problems including plagiarism, English grammar under par, and quality of content were rejected. Most papers that were ultimately accepted required several rounds of revision. Finally, 49 papers with quality content were accepted for publication in the Technology and Health Care journal. The journal is increasing in stature with each year, and is indexed in PubMed. We would like to thank the publisher and editor-in-chief of Technology and Health Care for the opportunity to develop the focus for this prestigious publication.

We believe that the readers of Technology and Health Care will enjoy perusing the papers presented herein, to obtain information on the latest technological advances in bioengineering and biotechnology. There is also the possibility to contact the authors for further information. We thank you for your interest, and hope that you will submit your latest work to the iCBEB 2017 meeting, to be held in Guangzhou, China, October 17th-20th, 2017 (http://www.icbeb.org/).

\footnotetext{
${ }^{*}$ Corresponding author: Edward J. Ciaccio, P\&S 7-446, Columbia University, 630 West 168th Street, New York, NY 10032, USA. E-mail: ciaccio@ columbia.edu.
}

0928-7329/17/ $\$ 35.00$ (c) 2017 - IOS Press and the authors. All rights reserved

This article is published online with Open Access and distributed under the terms of the Creative Commons Attribution NonCommercial License (CC-BY-NC 4.0). 